\title{
Fraturas odontomaxilares e mandibulares em eqüídeos tratados por diferentes técnicas de osteossíntese
}

\author{
[Odontomaxillares and mandibularies fractures in equides \\ treated with different osteosynthesis techniques] \\ G.E.S. Alves ${ }^{1}$, G.M. Pagliosa ${ }^{2 *}$, H.P. Oliveira ${ }^{1}$, V.A. Gheller ${ }^{1}$, R.R. Faleiros ${ }^{1}$ \\ ${ }^{1}$ Escola de Veterinária-UFMG - Belo Horizonte, MG \\ ${ }^{2}$ Aluna de pós-graduação - EV-UFMG - Belo Horizonte, MG
}

\begin{abstract}
RESUMO
Oito eqüinos e um muar com fraturas odontomaxilares e mandibulares foram tratados com diferentes técnicas de osteossíntese modificadas, consistindo de cerclagens associadas ou não a bandas de tensão, placa de neutralização e pino intraosseo, sendo este aplicado com metodologia não encontrada na literatura consultada. Os procedimentos cirúrgicos nos eqüideos foram realizados com os animais em estação mediante contenção física, em brete, e química, com sedação ou neuroleptoanalgesia associada a bloqueios anestésicos regionais. Os animais apresentaram capacidade de mastigação e ingestão voluntária no pós-operatório imediato e recuperação óssea adequada.
\end{abstract}

Palavras-chave: eqüino, fratura, odontomaxila, odontomandibular, osteossíntese

\begin{abstract}
Eight equines and one mule with odontomaxillaries and mandibularies fractures were treated with different osteosynthesis modified techniques, consisting of cerclages with or without tension bands, neutralization plates, and intraosseous pin applied by a methodology which was not found in the literature. The surgery procedures in equides were performed with the animals in stand position under physical contention, sedation, or neuroleptoanalgesy and regional nerve block. All animals were able to eat voluntarily in the immediate post-operatory time and had good bone recuperation.
\end{abstract}

Keywords: horse, fracture, odontomaxilar, mandibula, osteosynthesis

\section{INTRODUÇÃO}

Os eqüídeos são freqüentemente expostos a traumas faciais devido a atividades atléticas, condições de manejo ou temperamento (Loppacher, 1987; Ragle, 1993; DeBowes, 1996). Normalmente, esses traumas resultam em fraturas nas regiões anteriores da maxila ou mandíbula, o que limita ou impede a preensão e trituração dos alimentos podendo levar a graus variáveis de morbidade devido à inapetência ou à anorexia ocasionadas pelo desalinhamento dentário e pela dor (Ragle, 1993; Valadão et al., 1994; Crabill e Honnas, 2002).
As osteossínteses odontomaxilares e mandibulares devem restaurar a morfologia óssea e o alinhamento dentário mediante imobilização das extremidades fraturadas, bem como o retorno imediato da função mastigatória, ambos fundamentais para minimizar o tempo de recuperação óssea (Loppacher, 1987; Tremaine, 1998). Adicionalmente, fraturas estabilizadas de forma inadequada podem retardar ou inviabilizar a consolidação ou ocasionar anormalidades na erupção ou oclusão dentárias, contribuindo para graus variáveis de morbidade (Ragle, 1993; Valadão et al., 1994; DeBowes, 1996; Crabill e Honnas, 2002).

Recebido em 11 de setembro de 2007

Aceito em 8 de outubro de 2008

*Autor para correspondência (corresponding author)

E-mail: geanepagliosa@gmail.com

Universidade Federal do Paraná - Rua Pioneiro, 2153 -

85950-000 - Palotina, PR. 
A técnica de osteossíntese mais utilizada em fraturas odontomaxilares e mandibulares é a cerclagem nos dentes adjacentes. Em fraturas mais extensas e instáveis, a cerclagem pode estar associada à tração em sentido caudal, com apoio entre o segundo e o terceiro pré-molares ou nos dentes caninos ou em perfuração mandibular, formando uma banda de tensão (Dart e Pascoe, 1987; Loppacher, 1987; Valadão et al., 1994; Tremaine, 1998). A maioria das abordagens descritas na literatura consultada foi realizada com eqüinos sob anestesia geral.

O objetivo deste trabalho foi descrever nove casos de fraturas odontomalixares e mandibulares em eqüídeos tratadas por técnicas de osteossíntese modificadas.

\section{MATERIAL E MÉTODOS}

Foram atendidos oito eqüinos e um muar portadores de fraturas odontomaxilares e mandibulares ocorridas em até 12 horas. Todos os animais manifestavam sinais clínicos de anorexia e sialorréia. Os eqüinos, com idades abaixo de cinco anos, mantidos semiestabulados, e as fraturas decorreram de autotrauma ao morderem anteparos rígidos, flexionando a cabeça e pescoço. No muar, a fratura resultou de acidente de trânsito. $\mathrm{O}$ exame físico possibilitou identificar o local da fratura pela creptação e desalinhamento dos dentes incisivos. Pelo exame radiológico, avaliaram-se a extensão e a natureza das fraturas (Tab. 1).

Os eqüinos (animais 1 a 8 ) foram operados em posição quadrupedal, mantidos em tronco de contenção e submetidos à contenção química com xilazina ${ }^{1}$ na dose de 0,5 a $1,0 \mathrm{mg} / \mathrm{kg}$ associada ou não a butorfanol ${ }^{2}$ na dose de 0,02 a $0,03 \mathrm{mg} / \mathrm{kg}$ por via intravenosa. Após lavagem oral com água corrente, efetuou-se o bloqueio dos nervos mandibular alveolar nos eqüinos com fraturas odontomandibulares (animais 1, 4, 5 e 8) e infraorbitário nos eqüinos com fraturas odontomaxilares (animais 2, 3, 6 e 7) com lidocaína $2 \%$ com volume entre 7 e $10 \mathrm{ml}$. Seguiu-se curetagem do foco de fratura para debridar a ferida e estimular novo sangramento. Realizou-se, então, outra lavagem com solução

${ }^{1}$ Laboratório König S.A. - Santana de Parnaíba-SP, Brasil.

${ }^{2}$ Fort Dodge Saúde Animal Ltda. - São Paulo, Brasil. saturada de cloreto de sódio até a retirada do excesso de sangue, coágulo e partículas de tecido alveolar e mucosa oral. Excetuando-se os dentes incisivos decíduos fracamente aderidos ao alvéolo, os demais foram mantidos e fixados nos incisivos adjacentes estáveis.

A técnica e o material empregado na osteossíntese foram determinados de acordo com a extensão e instabilidade do foco de fratura (Tab. 1). Nos animais 2, 3, 6, 7 utilizou-se apenas a cerclagem nos incisivos adjacentes estáveis com fio de aço de 1,2mm (Fig. 1). Nos eqüinos 1,4 e 5 optou-se pela cerclagem com banda de tensão apoiada em dois pontos, um rostral nos incisivos adjacentes estáveis, e um caudal que variou dependendo da instabilidade e extensão da fratura. Na região mediana da banda de tensão, o fio de aço foi captonado com fragmentos de equipo de soro (Fig. 2c).

No animal 1, o apoio caudal da banda de tensão foi em um parafuso cortical de $3,5 \mathrm{~mm}$ fixado no ramo mandibular imediatamente anterior ao segundo pré-molar, em posição dorsolateral (Fig. 2). No animal 4, o apoio caudal foi em perfuração mandibular e, no animal 5, o apoio caudal foi em uma ranhura criada na borda caudal do dente incisivo.

No animal 8, a utilização de cerclagem foi impossibilitada devido à perda de quatro dentes incisivos, optando-se, portanto, pela fixação com pino de aço inox de $2,0 \mathrm{~mm}$. Após a redução da fratura, o pino foi inserido em sentido crâniocaudal, a partir do fragmento alveolar rostral, ao lado do dente incisivo remanescente até o diastema, emergindo próximo à papila salivar e paralelo à sínfese mandibular. Após a inserção, as respectivas extremidades do pino foram seccionadas e dobradas em forma de cravo para permitir a fixação adequada em suas extremidades emergentes (Fig. 3).

Após a osteossíntese, utilizou-se resina acrílica autopolimerizável ${ }^{3}$ sobre as cerclagens (animais $1,2,3,4,5,6$ e 7 ; Fig. 1 e 2) e sobre os pinos (animal 8; Fig. 3). Para minimizar o aquecimento durante a polimerização da resina, esta foi coberta com uma compressa umedecida em solução fisiológica.

\footnotetext{
${ }^{3}$ Artigos Odontológicos Clássico - Lapa-SP, Brasil.
} 


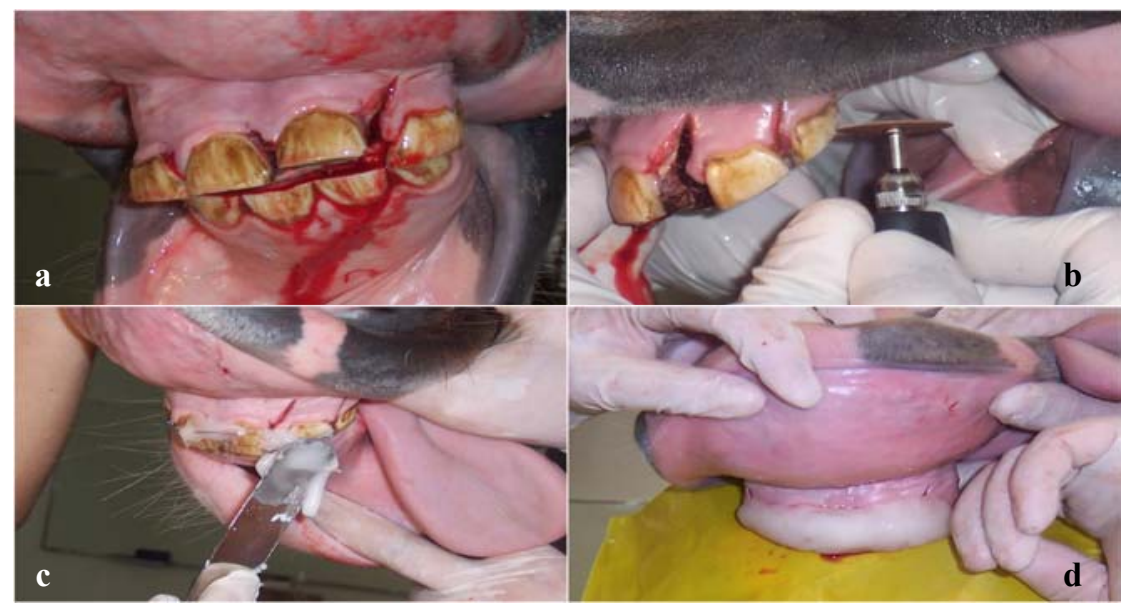

Figura 1. Eqüino (animal 6) portador de fratura odontomaxilar, acometendo os dentes incisivos pinças e médio esquerdo (a). Preparo do apoio da banda de tensão no incisivo canto esquerdo (b). Cobertura da banda de tensão com resina acrílica $(\mathrm{c}-\mathrm{d})$.

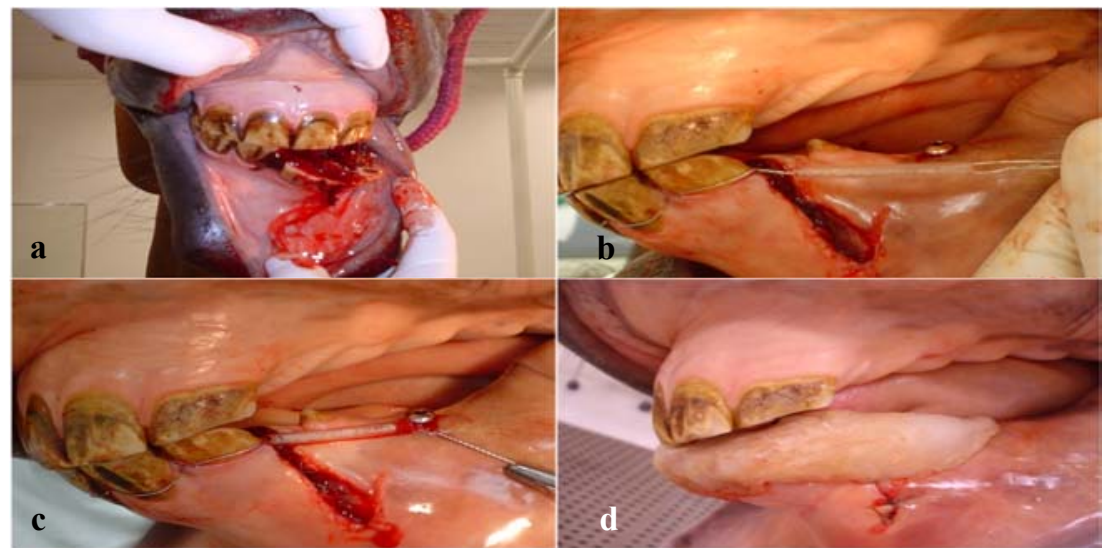

Figura 2. Eqüino (animal 1) portador de fratura odontomandibular, acometendo os dentes incisivos pinça, médio e canto esquerdos (a). Revestimento parcial da banda de tensão com segmento de equipo (b). Ancoragem da banda de tensão no parafuso cortical fixado na face dorsolateral da mandíbula. Nota-se o fio de aço captonado com equipo de soro (c). Cobertura da banda de tensão com resina acrílica (d).

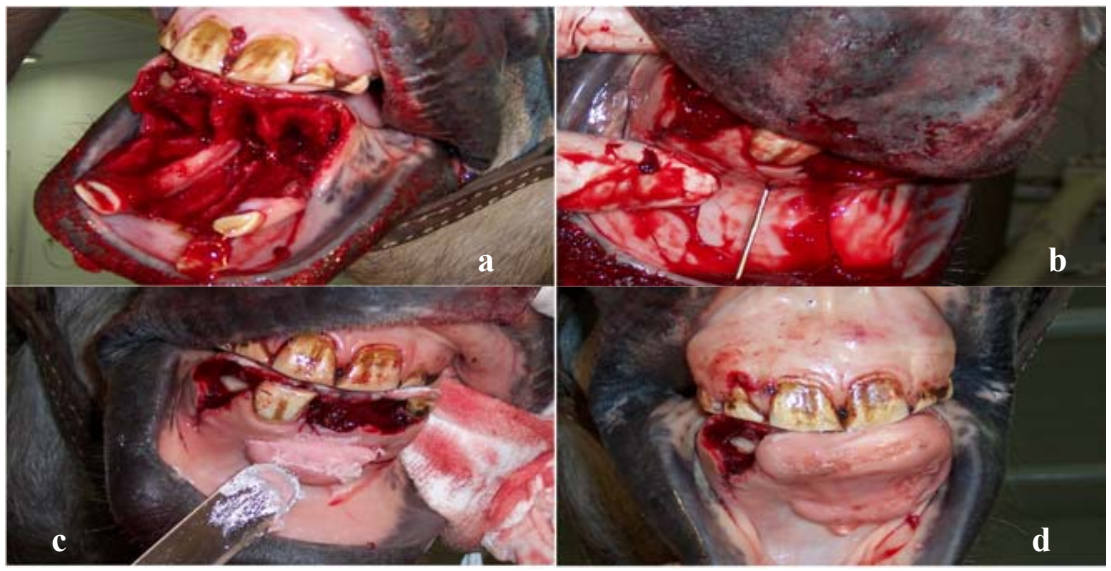

Figura 3. Eqüino (animal 8) portador de fratura odontomandibular com perda de incisivos - (uma pinça, médios, e um canto) - (a). Pino inserido pela mandíbula no sentido crâniocaudal, adjacente a pinça e a sínfise - (exteriorizado na face lingual e dobrado como grampo nas extremidades antes aparadas) - (b). Cobertura da dobra externa do pino e dos dentes remanescentes com resina acrílica $(\mathrm{c}-\mathrm{d})$. 
O muar, submetido à anestesia geral inalatória, foi posicionado em decúbito dorsal para a osteossíntese devido à fratura ser bilateral nas regiões dos diastemas mandibulares, além da dificuldade maior de manejo devido ao temperamento próprio da espécie. Para a fixação, utilizaram-se duas placas de neutralização de $6,0 \mathrm{~cm}$ e oito parafusos corticais de $20 \times 2 \mathrm{~mm}$.

Foi oferecida forragem tenra à base de capimelefante Pennisetum purpureum a todos os animais no pós-operatório imediato após o término dos efeitos da sedação ou anestesia. Durante o período pós-operatório administraramse $4,4 \mathrm{mg} / \mathrm{kg}$ de fenilbutazona ${ }^{4}$ por via intravenosa e $20.000 \mathrm{UI} / \mathrm{kg}$ de penicilina ${ }^{5}$ por via intramuscular durante três e sete dias, respectivamente. Foi realizada lavagem oral diária com solução antisséptica à base de iodovinilpirrolidona $^{6}$ diluída a $0,1 \%$. $\mathrm{Na}$ interface da mucosa oral com o acrílico foi aplicada solução de rifocina spray ${ }^{7}$.

Após a osteossíntese, os animais foram avaliados clinicamente, levando-se em conta especialmente a capacidade de preensão e mastigação do alimento, além da manutenção da estabilidade da fratura reduzida. Não foi realizada avaliação radiográfica.

A partir de seis semanas após o procedimento, os eqüinos foram submetidos a nova sedação para a retirada da resina acrílica e fio de aço e, após 12 semanas, as placas e os parafusos foram removidos do muar sob anestesia geral.

\section{RESULTADOS E DISCUSSÃO}

O exame físico possibilitou diagnosticar todas as fraturas de originais de autotrauma, tendo, por isso, características típicas de fraturas por avulsão. A abordagem cirúrgica em estação não acarretou dificuldades de operacionalidade para o cirurgião, e a sedação ou neuroleptoanalgesia, somada aos bloqueios anestésicos, foram suficientes para efetuar os procedimentos cirúrgicos. As técnicas de osteossíntese utilizadas foram consideradas adequadas, pois possibilitaram a restituição da estabilidade e a

\footnotetext{
${ }^{4}$ Marcolab - Duque de Caxias, Brasil.

${ }^{5}$ Intervet do Brasil Veterinária Ltda. - São Paulo, Brasil.

${ }^{6}$ Indústria de Produtos Naturais Ltda. - Campo Mourão-PR, Brasil.

${ }^{7}$ Hoeschst Marion Roussel - São Paulo, Brasil.
}

oclusão dentária, permitindo, assim, a retomada da fisiologia mastigatória.

Em todos os animais, o tempo de seis a 12 semanas foi suficiente para a retirada do material de osteossíntese, não se verificando, nessa ocasião, desalinhamento dentário. No muar, ocorreram fístulas e produção de exsudato de ambos os lados operados, as quais progrediram após a retirada das placas e parafusos e tratamento com solução de salina hipertônica. No entanto, tais ocorrências não impediram o reparo ósseo.

O diagnóstico de fraturas odontomaxilares e mandibulares pode ser realizado, na maioria dos casos, somente mediante exame clínico, sendo o exame radiológico um recurso auxiliar indispensável para a avaliação precisa da extensão e natureza da fratura (Ragles, 1993; Valadão et al., 1994; DeBowes, 1996). As alterações orais são características evidentes, o que torna fácil a identificação por parte do proprietário ou tratador, auxiliando $\mathrm{o}$ encaminhamento precoce dos animais ao veterinário.

O autotrauma, como ocorreu nestes casos, é um dos principais fatores na gênese de fraturas odontomaxilares e mandibulares, especialmente em animais jovens e confinados (DeBowes, 1996). A fratura típica nesse tipo de autotrauma é de avulsão, motivo pelo qual é comum a perda dentária (Ragle, 1993; DeBowes, 1996). No entanto, é indicada a manutenção dos dentes no alvéolo durante a osteossíntese (Valadão et al., 1994; DeBowes, 1996; Crabil e Honnas, 2002). Em todos os animais, isso foi possível excetuando-se o eqüino 8 (Fig. 3). Neste animal, a perda alveolar acentuada não permitiu a manutenção dentária.

Apesar de a cirurgia com os animais em estação quadrupedal somente ser considerada na literatura para os casos de fraturas odontomaxilares ou mandibulares de pouca instabilidade, essa conduta foi utilizada em todos os eqüinos, incluindo aqueles com instabilidade pronunciada no foco de fratura, animais $1,4,5$ e 8 . 
Tabela 1. Dados relativos à espécie, raça, osso acometido, região da fratura, técnicas de osteossíntese e material utilizado na redução de fraturas odontomaxilares e mandibulares em nove eqüídeos

\begin{tabular}{|c|c|c|c|c|c|}
\hline Animal & Espécie & Raça & $\begin{array}{c}\text { Osso } \\
\text { acometido }\end{array}$ & $\begin{array}{l}\text { Região da } \\
\text { fratura }\end{array}$ & $\begin{array}{c}\text { Técnicas de osteossíntese e materiais } \\
\text { utilizados }\end{array}$ \\
\hline 1 & Eqüino & $\mathrm{BH}$ & Mandíbula & Incisiva & $\begin{array}{l}\text { Apoio rostral em cerclagem dos incisivos } \\
\text { com fio de aço e apoio caudal unilateral } \\
\text { em parafuso cortical; cobertura com resina } \\
\text { acrílica }\end{array}$ \\
\hline 2 & Eqüino & $\mathrm{BH}$ & Maxila & Incisiva & $\begin{array}{l}\text { Cerclagem dos dentes incisivos com fio de } \\
\text { aço; cobertura com resina acrílica }\end{array}$ \\
\hline 3 & Eqüino & $\mathrm{CA}$ & Maxila & Incisiva & $\begin{array}{l}\text { Cerclagem dos dentes incisivos com fio de } \\
\text { aço: cobertura com resina acrílica }\end{array}$ \\
\hline 4 & Eqüino & $\mathrm{MM}$ & Mandíbula & Incisiva & $\begin{array}{l}\text { Apoio rostral em cerclagem dos incisivos } \\
\text { com fio de aço e apoio caudal em } \\
\text { perfuração na mandíbula; cobertura com } \\
\text { resina acrílica }\end{array}$ \\
\hline 5 & Eqüino & MM & Mandíbula & Incisiva & $\begin{array}{l}\text { Apoio rostral em cerclagem dos dentes } \\
\text { incisivos com fio de aço e apoio caudal } \\
\text { nos caninos; cobertura com resina acrílica }\end{array}$ \\
\hline 6 & Eqüino & MM & Maxila & Incisiva & $\begin{array}{l}\text { Cerclagem dos dentes incisivos com fio de } \\
\text { aço; cobertura com resina acrílica }\end{array}$ \\
\hline 7 & Eqüino & MM & Maxila & Incisiva & $\begin{array}{l}\text { Cerclagem dos dentes incisivos com fio de } \\
\text { aço; cobertura com resina acrílica }\end{array}$ \\
\hline 8 & Eqüino & $\mathrm{BH}$ & Mandíbula & Incisiva & $\begin{array}{l}\text { Inserção de pino de aço inox em sentido } \\
\text { craniocaudal a partir da gengiva incisiva } \\
\text { até o diastema, pararelo à sínfise } \\
\text { mandibular; cobertura das extremidades } \\
\text { dobradas do pino com resina acrílica }\end{array}$ \\
\hline 9 & Muar & SRD & Mandíbula & Diastema & $\begin{array}{l}\text { Placas de neutralização com quatro } \\
\text { parafusos em cada face lateral do diastema } \\
\text { mandibular }\end{array}$ \\
\hline
\end{tabular}

A maioria das abordagens cirúrgicas referidas na literatura consultada foi realizada com os eqüinos sob anestesia geral. Esta, apesar de proporcionar maior comodidade para o cirurgião, acarreta riscos maiores ao paciente quando comparada às abordagens cirúrgicas com eqüinos em posição quadrupedal. Adionalmente, a abordagem cirúrgica com os animais em posição quadrupedal apresenta as vantagens de ser menos onerosa, ser praticada no haras, não depender do transporte do animal e possibilitar o atendimento rápido do paciente.

As bandas de tensão utilizadas (animais 1, 4 e 5) foram realizadas mediante modificações das técnicas de Loppacher (1987) e Valadão et al. (1994), considerando-se o material disponível na ocasião dos atendimentos. O apoio caudal entre o segundo e terceiro pré-molares, como recomendado na literatura para reduzir fraturas de instabilidade pronunciada (Loppacher, 1987; Ragle, 1993; Tremaine, 1998), não foi adotado, evitando-se que a banda de tensão ficasse elevada em relação ao diastema e à mucosa oral, além de mais extensa.

O parafuso cortical como apoio caudal da banda de tensão foi anteriormente utilizado por Loppacher (1987) em fratura odontomaxilar, semelhante à tratada no animal 1 . No entanto, o autor não utilizou resina acrílica, o que resultou em acúmulo de alimento sob a banda de tensão e a necessidade de lavagens orais mais freqüentes. Nos casos relatados, em que se utilizou cerclagem com fio de aço, considerou-se o uso de resina acrílica indispensável pelo fato de proporcionar conforto e adaptação dos animais ao fio de aço e evitar o acúmulo de alimentos entre o fio e a mucosa oral, o que pode gerar estomatite e halitose. Adicionalmente, o uso de resina acrílica diminuiu o risco de afrouxamento da banda de tensão e auxiliou na manutenção da estabilidade da fratura já reduzida, observação também feita por Valadão et al. (1994). 
Não foi encontrada na literatura a descrição da redução de fraturas odontomandibulares por meio de pino de aço conforme descrito no eqüino 8 deste relato. A estabilidade adequada da fratura reduzida permitiu a ingestão voluntária de alimento no pós-operatório imediato. $\mathrm{O}$ eqüino apresentou ptialismo discreto nos três dias subseqüentes à intervenção cirúrgica, o que se suspeitou ser devido à proximidade do gancho caudal feito no pino com a papila salivar. Semelhante às fraturas reduzidas com fio de aço e pelos motivos já expostos, considerou-se a resina acrílica indispensável no auxílio da estabilidade da fratura reduzida e na prevenção do acúmulo de alimento no local da osteossíntese.

A avaliação clínica baseada nos sinais, presença de apetite e capacidade de preensão, mastigação e deglutição dos alimentos foi considerada adequada para avaliação imediata da eficiência dos procedimentos cirúrgicos nos eqüídeos desse relato. A capacidade de ingestão voluntária permitiu inferir que foi restituído o alinhamento dentário e conferida estabilidade adequada à fratura reduzida, uma vez que a instabilidade é um dos principais estímulos algogênicos em pacientes portadores de fraturas (Radash, 1999).

\section{CONCLUSÕES}

As técnicas de cerclagem com fio de aço e a banda de tensão associadas à resina acrílica promoveram estabilidade adequada após a redução de fraturas odontomaxilares e mandibulares em eqüinos, podendo-se utilizar o pino de aço, na impossibilidade de emprego dessas técnicas. A abordagem cirúrgica com os eqüinos em posição quadrupedal é possível, mesmo em fraturas de instabilidade pronunciada mediante contenção física e farmacológica, além de bloqueio anestésico regional. Os sinais clínicos de preensão, mastigação e ingestão de alimento são úteis na avaliação imediata do procedimento cirúrgico.

\section{REFERÊNCIAS BIBLIOGRÁFICAS}

CRABILL, H.R.; HONNAS, C. Mandibular and maxillary fracture osteosyntesis. In: BAKER, G.J.; EASLEY, J. (Ed). Equine dentisty. London: Saunders, 2002. p.259-270.

DART, A.J.; PASCOE, R.R. Treatment of a bilateral mandibular fracture in a mare using an intraoral acrylic splint. Aust. Vet. J., v.64, p.382384, 1987.

DeBOWES, R.M. Fractures of the mandible and maxilla. In: NIXON, A.J. (Ed). Equine fracture repair. Philadelphia: Saunders, 1996. p.323-336.

LOPPACHER, R. Mandibular and maxillary fractures: a review of 46 cases. 1987.[s.n.]f. Dissertation (Master) - University of Zürich, Zürich.

RADASH, R.M. Biomechanischis of bone and fractures. Vet. Clin. N. Am.: Small Anim. Pract., v.29, p.1045-1082, 1999.

RAGLE, C.A. Head trauma. Vet. Clin. N. Am.: Equine Pract., v.9, p.171-183, 1993.

TREMAINE, W.H. Management of equine mandibular injuries. Equine Vet. Educ., v.10, p.146-154, 1998.

VALADÃO, C.A.A.; MARQUES, J.A.; PADILHA FILHO, J.G. et al. Uso de cerclagem e resina acrílica em fraturas mandibulares dos eqüideos. Cienc. Rural, v.24, p.323-327, 1994. 